\title{
Occurrence and Distribution of Soybean Sudden Death Syndrome in Iowa
}

\author{
X. B. Yang, Assistant Professor, and P. Lundeen, Research Associate, Department of Plant Pathology, Iowa State \\ University, Ames 50011
}

\begin{abstract}
Yang, X. B., and Lundeen, P. 1997. Occurrence and distribution of soybean sudden death syndrome in Iowa. Plant Dis. 81:719-722.

Soybean sudden death syndrome (SDS), caused by blue-pigmented, slow-growing strains of Fusarium solani, is a disease recently reported in Iowa. In 1994 and 1995 the geographic distribution and status of the disease was determined at the state, local, and field levels. An east-towest decreasing trend of SDS prevalence was found at the state level. No SDS was found in the western part of Iowa. The disease was found in commercial production fields in 4 Iowa crop reporting districts - central, north-central, east-central, and southeastern - with the greatest severity and the most frequent occurrence of SDS found in the east-central district. In two counties along the Mississippi River, disease prevalence was high; more than 50\% of soybean fields had SDS in locations where surveys were conducted. Intensive surveys on a local scale were conducted in areas around the fields where the disease was first noticed. In areas where disease prevalence was low, all detected infested fields belonged to the same owners. In areas where disease prevalence was high, no such pattern was found. Disease incidence varied from field to field. Information on SDS occurrence at different geographic scales serves as baseline information to monitor the future development of the disease in Iowa.
\end{abstract}

Additional keywords: disease detection, epidemiology, scale, soilborne disease

Soybean sudden death syndrome (SDS) is caused by blue-pigmented, slow-growing strains of Fusarium solani (Mart.) Appel \& Wollenweb. emend Snyd. \& Hans $(7,8)$. The disease appears after flowering and can cause defoliation and pod abortion. The disease generally occurs in fields where yield potentials are high, and yield losses up to $50 \%$ have been observed in Arkansas (10). SDS was first noticed in Arkansas in 1971 as a disease with unknown cause. It was reported from Tennessee, Missouri, and Mississippi in 1984 and from Illinois, Kentucky, Kansas, and Indiana in $1985(10,15)$. In 1993, Hartman et al (3) reported epidemics in east-central Illinois, with SDS occurring in $46 \%$ of the soybean fields. Although SDS has been found in many regions, little information on the geographic distribution of this disease has been documented beginning with the initial report of the disease in a given area.

SDS was first found in Iowa, the northernmost state where SDS has been reported, in experimental plots in 1993 (16). Information on the prevalence and distribution of SDS in Iowa may serve as a baseline for future examination of the development of this disease in Iowa as well

Corresponding author: X. B. Yang

E-mail: xbyang@iastate.edu

Accepted for publication 24 March 1997.

Publication no. D-1997-0425-06R

(C) 1997 The American Phytopathological Society as in the North Central Region if SDS indeed is at an early stage of spread into this region. Further, information on prevalence and distribution of the disease is essential, (i) to assess the economic importance of SDS to Iowa soybean production and to prioritize research needs in the long term, and (ii) to develop strategies to prevent the future spread of this disease in the state. Thus, the objective of this study was to determine and document the prevalence and distribution of the disease in Iowa soybean production fields.

\section{MATERIALS AND METHODS}

Survey and SDS identification. SDS was first found in experimental plots in Iowa (16) in 1993, but the disease was not found that year in a preliminary survey conducted in commercial soybean fields in central and southeastern Iowa. In 1994 and 1995, we conducted a more extensive survey using a multiscale (state, local, and field) approach to determine the occurrence and status of SDS in Iowa. Different sampling approaches were used for different scales (see below).

In this study, identification of SDS and its causal agent was made based on symptoms, and colony and spore morphology $(7,8)$. Because $90 \%$ of soybean fields in Iowa are infested with Phialophora gregata (12), a fungus that causes soybean brown stem rot (BSR) with foliar symptoms similar to those of SDS, stems of symptomatic soybean plants were dissected and examined for internal browning of the pith, a symptom characteristic of only BSR. Also, roots of symptomatic plants were examined because SDS causes root decay and BSR does not . Roots of symptomatic plants were tested for presence of bluish strains of $F$. solani by plating on acidified potato dextrose agar (APDA) or modified Nash-Snyder medium (J. C. Rupe, personal communication). Pathogenicity of $F$. solani isolates was tested on soybean cv. BSR 101 in the greenhouse with previously described procedures $(5,7)$. An Arkansas isolate 171 (J. C. Rupe, University of Arkansas) was used as a control.

Surveys at the field scale. We estimated the size of the diseased patches and disease intensity in fields where SDS was found. Information of SDS occurrence on a field scale is useful to estimate the history of infestation because the pattern and extent of infestation of SDS in a field may be related to years of infestation. The extent of infestation with SDS in a field was arbitrarily defined into three levels: (i) fields having scattered diseased plants, (ii) fields where diseased plants formed one or a few small patches with areas of less than 100 $\mathrm{m}^{2}$, and (iii) fields having one or more large patches of diseased plants with patch sizes ranging from $100 \mathrm{~m}^{2}$ to 1 ha $(10,000$ $\mathrm{m}^{2}$ ). Two to three fields representing each level of infection were sampled for detailed disease assessment. Two variables - disease incidence, defined as percentage of plants with leaves having interveinal chlorosis or necrosis, and disease severity, defined as percentage loss of green leaf area - were estimated. The distribution of the disease in a few selected fields was mapped by sketching the sizes and locations of individual patches. The shape of individual patches was estimated from observations, and the length and width of the patches were measured in the field. The location of a patch in the field was determined as the distance from the border of the field to the patch edge.

Occurrence in local areas. In a local area, which was defined as an area of 28 to $71 \mathrm{~km}^{2}$, we attempted to determine the intensity of infection around fields where SDS was first found in a given area. Because $F$. solani is soilborne, information on the occurrence of the disease at the local level can provide clues as to how the pathogen spreads from field to field. Occurrence of SDS within the local area was examined at five locations to determine the distribution and prevalence of the disease in a defined area. At each location, a survey area was defined with the first identified diseased field serving as a center for distance measurements. Fields in the de- 
fined area around the center field were mapped as soybean, corn, or alfalfa/pasture fields on a section map. Each soybean field in these sections was first examined for plants with SDS symptoms in a zigzag sampling pattern. Special examination was then given to areas of field entry or lower areas where moisture is high and disease is more likely to occur (10). When a second diseased field was found, data on disease occurrence were collected as already described. Information on ownership, planting date, tillage, soil type, and variety of soybean was obtained for each field where SDS was found. Studies at this level were conducted in five counties (one location each county): Black Hawk, Story, and Washington County in 1994, and Clinton and Scott County in 1995.

Occurrence in the state. The occurrence of SDS at the state level was determined by using two approaches, a systematic survey and a clinical approach. A systematic survey was conducted to determine the prevalence of SDS in the nine crop reporting districts of Iowa. Surveys were conducted after pod set, R3 (2), from late July to late August in 1994 and 1995.
In each district, 15 to 25 sampling points (except for south-central district) were arbitrarily selected to cover the major soybean production areas with distances of at least $15 \mathrm{~km}$ between two neighboring sampling points. At each sampling point, one or two soybean fields were examined. When SDS was found, plants were assessed for disease severity and plant samples were collected and taken to the laboratory for further examination.

Information from the Iowa State University Plant Disease Clinic was used for the clinic survey. The approach of clinical surveys has been widely used by medical epidemiologists in statistical surveys. After the initial account of SDS in Iowa in 1993, soybean samples suspected of having SDS were submitted to the plant disease clinic by soybean producers and agronomists in the public and private sectors for identification. We examined plant samples for SDS foliar symptoms and presence of $F$. solani in the roots. If the plants had symptoms of SDS and $F$. solani was present, the fields were further investigated. Field investigations included examination of SDS symptoms and collection of disease inci-

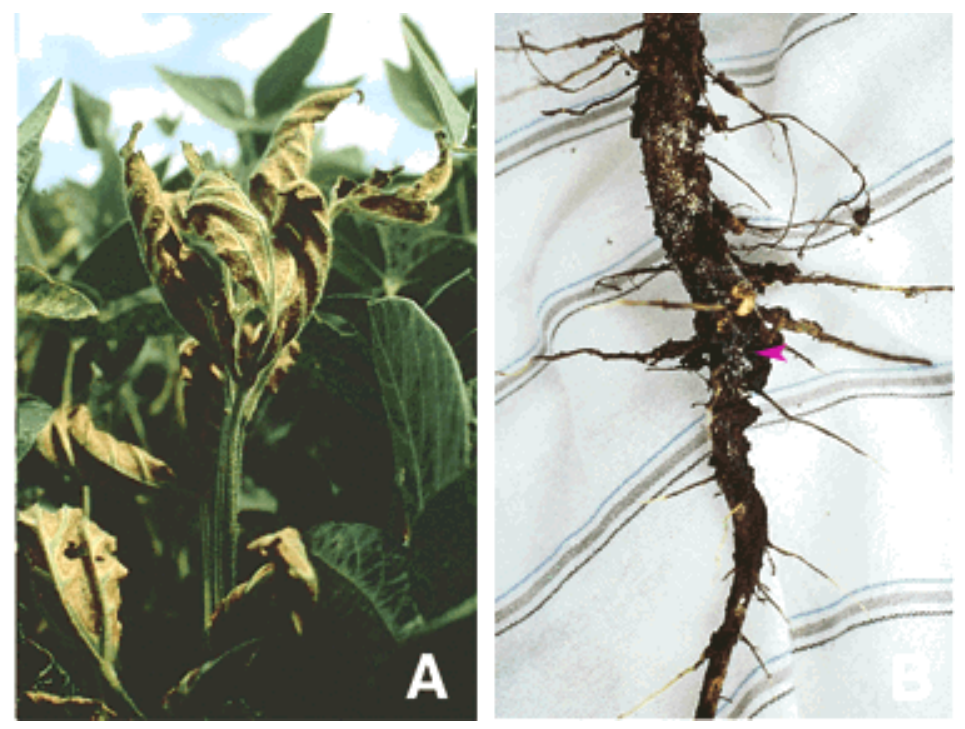

Fig. 1. Soybean sudden death syndrome (caused by blue-pigmented, slow-growing strains of Fusarium solani) in commercial production fields in Iowa. (A) foliar symptoms found in Black Hawk County; (B) roots with spore production (arrow) found in Scott County.

Table 1. Number of soybean fields examined and fields where soybean sudden death syndrome was found (caused by blue-pigmented, slow-growing Fusarium solani) by crop reporting districts in Iowa in systematic surveys during 1994 and 1995 soybean reproductive seasons (stages R2-R4) ${ }^{\mathrm{a}}$

\begin{tabular}{lccc}
\hline Region & Counties covered & Fields examined & Fields with SDS \\
\hline Southwest & 5 & 25 & 0 \\
West central & 4 & 18 & 0 \\
Northwest & 4 & 17 & 0 \\
South central & 3 & 7 & 0 \\
Central & 10 & 48 & 0 \\
North central & 6 & 28 & 0 \\
Southeast & 5 & 30 & 0 \\
East central & 5 & 21 & 1 \\
Northeast & 6 & 17 & 0 \\
Total & 48 & 211 & 1 \\
\hline
\end{tabular}

${ }^{a}$ Reproductive soybean growth stage (2). dence and severity data, and determination of size of diseased patches. Information about planting dates, varieties, and cultural practices also was collected. A field was confirmed as SDS-infested only when isolation and symptoms were positive. The pattern of geographic occurrence of SDS in Iowa was determined by pooling all SDS data and sorting the data into three regions: eastern, central, and western. The number of SDS-infested fields and the levels of infestation of these fields were determined for each region. The data were then summarized by crop-reporting district to examine the geographical distribution of this disease within the state.

\section{RESULTS}

Occurrence at the field level. Sudden death syndrome was found in production fields in 1994 and 1995. In 1994, all fields where SDS was observed had been planted before May, which represents early planting in Iowa. The earliest symptoms were observed on 11 July at flowering stage from a field in Black Hawk County in 1994. In 1995, because of a wet and cold spring in Iowa, soybean planting was delayed beyond May and the first symptoms were observed in late July. Symptoms first appeared on leaves as scattered, interveinal, chlorotic spots or blotches which became necrotic, with midvein and major lateral veins remaining green and the leaves curled upward (Fig. 1A). Severely affected leaflets often dropped off, leaving the petioles attached to the stem. Root symptoms included deterioration of taproots and lateral roots. In some fields where soil moisture was high when samples were taken, blue-pigmented fungal structures were visible on the roots (Fig. 1B). Slow-growing, blue-pigmented strains of $F$. solani were isolated from roots of diseased plants, and these strains produced abundant macroconidia matching morphological descriptions by Roy et al (7) and Rupe (8). All F. solani isolates tested caused SDS symptoms on inoculated plants at growth stage V3 (cultivar BSR 101) in the greenhouse

The frequency of occurrence and severity of disease varied from field to field. In Story County in 1994, a 16-ha field had an average incidence of $0.1 \%$, with the highest disease level found near the entry to the field. No diseased plants were found on the opposite side of the field. In a field in Washington County in 1994, there were small patches where severe defoliation occurred and a larger patch (about $1 \mathrm{ha}$ ) that also had severe defoliation. The early defoliation was followed by flower and pod abortion, with some plants in these patches having no pods. In a field at Scott County in 1995, there were 3 large disease patches, accounting for about $25 \%$ of the area of this 12-ha field.

Occurrence at the local level. Of all locations where SDS was found, 3 types of 
local patterns were identified based on disease levels and distribution: (i) light infection with limited local distribution (infested fields always belonged to the same owners, an indication of spread with soil movement by farm equipment), (ii) limited local distribution, mostly light infection except for one or two fields with severe infection, and (iii) widespread over a location. An area in Story County represented the first type, where 62 soybean fields were distributed in a $71 \mathrm{~km}^{2}$ area. Only 2 fields were found having SDS. The second field was $3.5 \mathrm{~km}$ away from the first one and belonged to the same owner. A location in Washington County represented the second type of distribution. In that location, 40 soybean fields were examined in a $44 \mathrm{~km}^{2}$ area. The center field had many small patches of diseased plants and 1 disease patch of 1 ha. Another SDSinfested field was found about $1 \mathrm{~km}$ from the first and also belonged to the same owner. At a location in Black Hawk County, 44 soybean fields were examined in a $41 \mathrm{~km}^{2}$ area and the two SDS-infested fields were owned by the same grower. Two areas along the Mississippi River represented the third type of distribution. In Scott County, a diseased field was first noticed at Princeton near the Mississippi River. An area covering $28 \mathrm{~km}^{2}$ and including 20 soybean fields was surveyed. SDS was found in 11 fields, 4 of which had large disease patches. On one farm, SDS plants were found in every field (3 fields total). A similar situation was found in a location in Clinton County, which also had a high disease prevalence. In the Scott County location, only 1 field out of 11 SDS-infested fields was in ridge-till, although ridge-till was widely used in this region.

Occurrence in the state. We systematically examined a total of 211 soybean fields, 109 fields in 1994 and 102 fields in 1995 , in 48 counties in the major soybean production areas of Iowa (Table 1). We examined 60 fields in western, 83 in central, and 68 in eastern Iowa. Only 7 fields were examined in south-central Iowa because this region has a small soybean acreage. No SDS-infested soybean fields were found in 1994. In 1995, 1 field in Clinton County in east-central Iowa was found with SDS diseased plants in a small patch (about $4 \mathrm{~m}^{2}$ ).
With clinical survey, we found SDS in the following counties in eastern and central Iowa: Black Hawk, Boone, Clinton, Des Moines, Floyd, Henry, Johnson, Jones, Marshall, Scott, Story, Washington, and Wright (Fig. 2). SDS-diseased plants were found in 25 fields in eastern and 5 in central Iowa districts (Table 2). Large patches of diseased plants were found 10 fields in eastern Iowa ( 2 in 1994 and 8 in 1995) in districts along the Mississippi River. Among the 10 fields, 7 were found in Scott and Clinton Counties, which are in the east-central district on the Mississippi River. Of the 5 fields found in central districts, 4 had scattered diseased plants, and only 1 had a small patch of diseased plants. No SDS-infested fields were found in any of the western Iowa districts in the 2-year study. The results indicate that SDS is more prevalent in eastern Iowa than in central and western Iowa.

\section{DISCUSSION}

This is the first report on the occurrence and distribution of SDS on state, local, and field scales that immediately followed the first notice of SDS in a new region. Our results showed that SDS is present in commercial soybean fields in at least 13 Iowa counties. Fields with severe damage of SDS were all found in east-central and southeastern Iowa districts, especially in counties along the Mississippi River. Our results suggest that SDS is most prevalent in eastern Iowa and overall severity in Iowa is low.

High levels of disease incidence and severity in individual fields suggest that SDS may have been in these fields for years without being noticed. For instance, some fields in Washington, Scott, and Clinton County had disease patches as large as 1 ha; it is very unlikely for a soilborne disease to establish and develop into such a large area in only 1 or 2 years. This is further supported by the study on the local level in an area near Princeton in Scott County, where SDS was first found in 1995; soybean plants in 55\% of examined fields (11 of 20 fields) showed SDS symptoms.

By using the clinical survey compared to the systematic survey, we increased the chance of detecting the disease in Iowa. Scouting efforts from agribusiness and other agriprofessionals enabled us to obtain information from a larger number of fields than we could cover systematically. The number of fields harboring the SDS pathogen, however, may be higher than what is reported here. Plants in some fields harboring the SDS pathogen may not exhibit symptoms because the environment may not be conducive to disease development. Previous studies $(6,10)$ showed that occurrence of SDS is highly dependent on environmental conditions.

That SDS-infested fields belonged to the same owner only in locations where the

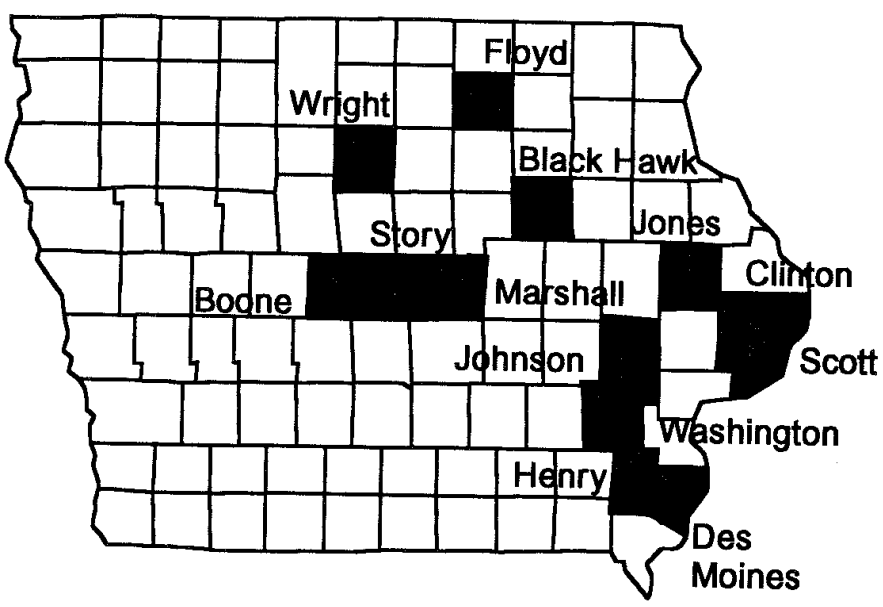

Fig. 2. Iowa counties where soybean sudden death syndrome (caused by blue-pigmented, slowgrowing Fusarium solani) was found.

Table 2. Number of soybean fields where sudden death syndrome (caused by blue-pigmented, slow-growing Fusarium solani) was found in eastern, central, and western Iowa. Fields were grouped according to the level of disease intensity

\begin{tabular}{lcccc}
\hline & & & \multicolumn{2}{c}{ Number of fields with different levels of disease } \\
\cline { 3 - 5 } Region & Fields where SDS was found & Counties SDS was found $^{*}$ & Scattered plants $^{\mathbf{a}}$ & Small patches $^{\mathbf{b}}$ \\
\hline Eastern & 25 & 9 & 4 & 11 \\
Central & 5 & 3 & 4 & 1 \\
Western & 0 & 0 & 0 & 0 \\
\hline
\end{tabular}

a Scattered: only scattered diseased plants were found.

b Small patch: diseased plants were aggregated in an area less than $100 \mathrm{~m}^{2}$.

${ }^{\mathrm{c}}$ Large patch: diseased plants were aggregated in areas as large as 1 ha. 
disease prevalence was low suggests that farming practices are important for the occurrence and spread of SDS. To our knowledge, spread of SDS pathogen in soil has not been verified. Because $F$. solani is soilborne, our observations suggest that the movement of soil with the equipment used for field operations may be a means for pathogen spread from field to field at a local level. To prevent the future spread of this disease in areas where the disease incidence is low, sanitation measures to reduce field-to-field soil movement may be effective.

Previous studies show that varieties $(9,11)$, planting date $(4,14)$, and tillage $(13,14)$ affect the occurrence of SDS. These factors may have affected the level of SDS occurrence during our surveys. In 1994, planting conditions were excellent, with many early plantings in Iowa that favor disease occurrence (10); all fields where SDS was found were planted in April. It is well-established that SDS severity is higher in early planted soybean compared with later planted soybean $(4,14)$. It is also interesting to notice that 4 fields out of the 8 initial fields found with SDS in 1994 were under no-till management, although only $20 \%$ of Iowa soybean fields were managed this way. Two studies $(13,14)$ showed that occurrence of SDS was more severe in no-till than in plowed fields. We also observed that ridge-tilled soybean fields had either little or no diseased plants in areas of 2 eastern counties where the disease prevalence was high. Wrather et al. (14) showed that SDS was less severe under ridge-tillage compared with other tillage. Use of ridge-till reduces water potential in the root zone, which may reduce conducive conditions for early infection (1).

In the last 20 years, SDS has developed from an endemic disease in Arkansas to a disease observed over a wide area of the United States, from Mississippi to Iowa and from Indiana to Kansas $(3,13,15,16)$. It is not known if the pathogens found in different states are the same or different in origin. Documentation of the spatial pattern of a new disease at its early stage should have value for the determination of the origin of the disease. Although SDS was reported in other states many years ago, little information has been accumulated on the occurrence of SDS over a long period in a given region. Our report is the first document on geographic distribution of SDS in a state. Our results are useful to study the spread and development of this soilborne disease on large spatial and temporal scales.

The distribution pattern found in this study provides a baseline to examine the future development of this disease in Iowa. In this study, no SDS-infested fields were found in western Iowa districts, and the most severely infested commercial fields were found in eastern Iowa districts along the Mississippi River. In 1993, Hartman et al (3) reported that about $46 \%$ of soybean fields in east-central Illinois were infested by SDS. If the pathogen in Iowa was introduced from Illinois, the disease may continue to spread westward and, therefore, we may see increased reports of SDS in central and western Iowa in the future. If the pathogen originated in Iowa but is limited in area along the Mississippi River where the environmental conditions may be conducive to the disease, the future distribution and prevalence of this disease are expected to change insignificantly. If the pathogen was introduced from other regions with no observed future expansion to central and western Iowa, we may conclude that, in Iowa, the disease is endemic in an area along the Mississippi River.

\section{ACKNOWLEDGMENTS}

We thank J. Rupe at the University of Arkansas for providing the recipe of modified selective medium; K. Elbasher, H. Ellison, R. Johnson, and J. Nelson for assistance during the investigation; and $\mathrm{H}$. Scherm for critical review.

\section{LITERATURE CITED}

1. Abney, T. S. 1994. Factors influencing sudden death syndrome and root health in soybean. Pages 45-47 in: Proceedings, 1994 Integrated Crop Management Conference, Iowa State University, Ames.

2. Fehr, W. R., Caviness, C. E., Burmood, D. T., and Pennington, J. S. 1971. Stage of development descriptions for soybeans, Glycine $\max (\mathrm{L})$ Merill. Crop Sci. 11:929-931.

3. Hartman, G. L., Noel, G. R., and Gray, L. E.
1995. Occurrence of soybean sudden death syndrome in east-central Illinois and associated yield losses. Plant Dis. 79:314-318.

4. Hershman, D. E., Hendrix, J. W., Stuckey, R. E., Bachi, P. R., and Henson, G. 1990. Influence of planting date and cultivar on soybean sudden death syndrome in Kentucky. Plant Dis. 74:761-766.

5. Killebrew, J. F., Roy, K. W., Lawrence, G. W., McLean, K. S., and Hodges, H. H. 1988. Greenhouse and field evaluation of Fusarium solani pathogenicity to soybean seedlings. Plant Dis. 72:1067-1070.

6. Mclean, K. S., and Lawrence, G. W. 1993. Interrelationship of Heterodera glycines and Fusarium solani in sudden death syndrome of soybean. J. Nematol. 25:434-439.

7. Roy, K. W., Lawrence, G. W., Hodges, H. H., McLean, K. S., and Killebrew, J. F., 1989. Sudden death syndrome of soybean: Fusarium solani as incitant and relation of Heterodera glycines to disease severity. Phytopathology 79:191-197.

8. Rupe, J. C. 1989. Frequency and pathogenicity of Fusarium solani recovered from soybeans with sudden death syndrome. Plant Dis. 73:581-584.

9. Rupe, J. C., Gbur, E. E., and Marx, D. M. 1991. Cultivar responses to sudden death syndrome of soybean. Plant Dis. 75:47-50.

10. Rupe, J. C., Hirrel, M. C., and Hershman, D. E. 1989. Sudden death syndrome. Pages 8485 in: Compendium of Soybean Diseases. J B. Sinclair and P. A. Backman, eds. 3rd edition. American Phytopathological Society, St. Paul, MN.

11. Stephens, P. A., Nickell, C. D., and Lim, S. M. 1993. Sudden death syndrome development in soybean cultivars differing in resistance to Fusarium solani. Crop Sci. 33:63-66.

12. Tachibana, H., and Booth, G. D. 1979. An efficient and objective survey method for brown stem rot of soybeans. Plant Dis. 63:539-541.

13. Von Qualen, R. H., Abney, T. S., Huber, D. M., and Schreiber, M. M. 1989. Effects of rotation, tillage, and fumigation on premature dying of soybeans. Plant Dis. 73:740 744.

14. Wrather, J. A., Kendig, S. R., Anand, S. C., Niblack, T. L., and Smith, G. S. 1995. Effects of tillage, cultivar, and planting date on percentage of soybean leaves with symptoms of sudden death syndrome. Plant Dis. 79:560 562.

15. Wylie, T. D. 1988. Soybean sudden death syndrome - current status. Pages $42-45$ in: Proc. Annu. Soybean Res. Conf. 18. Washington D.C

16. Yang, X. B., and Rizvi, S. S. A. 1994. First report of sudden death syndrome of soybean in Iowa. Plant Dis. 78:830. 